\title{
An Evaluation of Longitudinal Measures of Anticholinergic Exposure for Application in Retrospective Administrative Data Analyses
}

\author{
Greta Lozano-Ortega - Shelagh M. Szabo (D) - Antoinette Cheung • \\ Brandon Suehs · Eleanor O. Caplan · Adrian Wagg • Noll Campbell • \\ Roger Dmochowski · Basia Rogula · Daniel B. Ng
}

Received: May 9, 2019 / Published online: August 5, 2019

(C) The Author(s) 2019

\section{ABSTRACT}

Introduction: As continuous exposure to anticholinergics has been associated with adverse outcomes, accurately measuring exposure is important. However, no gold standard measure is available, and the performance of existing measures has not been compared. Our objective was to compare the properties of the Cumulative Anticholinergic Burden (CAB) measure against two existing measures of anticholinergic exposure and to assess their compatibility for

Enhanced Digital Features To view enhanced digital features for this article go to https://doi.org/10.6084/ m9.figshare. 8864867 .

Electronic supplementary material The online version of this article (https://doi.org/10.1007/s12325019-01035-z) contains supplementary material, which is available to authorized users.

G. Lozano-Ortega · S. M. Szabo ( $₫) \cdot$ A. Cheung · B. Rogula

Broadstreet Health Economics and Outcomes

Research, 203-343 Railway St., Vancouver, BC V6A

1A4, Canada

e-mail: sszabo@broadstreetheor.com

B. Suehs · E. O. Caplan

Humana Healthcare Research Inc, 500 West Main

St., Louisville, KY 40202, USA

A. Wagg

University of Alberta, 1-198 Clinical Sciences

Building, 11350- 83 Ave., Edmonton, AB T6G 2P4,

Canada use in observational studies based on claims data.

Methods: The average daily dose, cumulative dose and $\mathrm{CAB}$ measures were evaluated on: the applicability for use with anticholinergic burden scales, the ability to consider duration and/ or accumulation of exposure, and consideration of anticholinergic dose, potency, and residual effect. To calculate each measure empirically, Truven MarketScan claims data from 2012 to 2015 were analyzed. Cumulative anticholinergic exposure over 1-year post-enrollment was calculated for each measure using Anticholinergic Cognitive Burden scale scores. Median [interquartile range (IQR)] and ranges of measure scores, and Spearman's correlation coefficients between measures, were estimated. Due to the differing methods of calculation, the absolute values of each score cannot be compared.

\section{N. Campbell}

College of Pharmacy, Purdue University, 575

Stadium Mall Drive, West Lafayette, IN 47907, USA

R. Dmochowski

Urologic Surgery, Vanderbilt University, 1211

Medical Center Drive, Nashville, TN 37232, USA

D. B. $\mathrm{Ng}$

Astellas Pharma Global Development Inc, 1 Astellas Way, Northbrook, IL 60062, USA 
Results: The properties of the different measures varied, with only the $\mathrm{CAB}$ considering both dose and theoretical potency. The cohort included 99,742 individuals (mean age $=73.1$ years; $54.9 \%$ female). Among individuals prescribed anticholinergics $(n=55,969)$, 1-year median (IQR) scores based on average daily dose, cumulative dose and $\mathrm{CAB}$ measures were 0.9 (0.3-1.5), 16.9 (7.3-33.9) and 203 (68-500), respectively. Measures were highly inter-correlated $\left(r^{2}=0.74-0.83\right)$.

Conclusions: Considering both potency and dose, the $\mathrm{CAB}$ may prove a more comprehensive measure of anticholinergic burden; however, additional research is necessary to demonstrate whether it has any association with relevant health-related outcomes.

Funding: Astellas Pharma Global Development, Inc.

Keywords: Anticholinergic; Burden; Claims analysis

\section{INTRODUCTION}

Medications with anticholinergic properties are frequently prescribed to older adults (those $\geq 65$ years of age) to manage conditions such as asthma, chronic obstructive pulmonary disease, depression, psychosis, Parkinson's disease, allergies and overactive bladder [1]. As these medications target acetylcholine receptors at multiple sites, unintended effects due to anticholinergic activity secondary to the primary purpose for which they were prescribed occur [2]. As such, patients with multiple comorbidities may accumulate higher levels of exposure following the prescription of multiple anticholinergics over long durations of time, and with that comes an increased risk of medication-related adverse effects [3]. This exposure is referred to in the literature as the anticholinergic burden [4].

While many studies have examined the anticholinergic burden cross-sectionally, only a handful of studies have evaluated the effects of cumulative exposure. In a prospective population-based cohort study, Gray et al. reported that cumulative anticholinergic use was associated with an increased risk of incident dementia [5]. In a retrospective cohort study, Campbell et al. reported that a higher anticholinergic burden was associated with a greater risk of cognitive impairment [6]. Richardson et al. observed an association between the majority of strongly anticholinergic medications (e.g., antiparkinsonian, antidepressant, or urologic medications) and incident dementia [7]. More recently, Szabo et al. reported that higher levels of cumulative anticholinergic burden were associated with a higher risk of falls and fractures in a population with an overactive bladder [8]. These associations, however, are challenging to investigate because of the often long latencies between exposure and outcomes. As administrative claims data can provide longitudinal information on medication dispensation and health outcomes, they represent a powerful and largely untapped resource for evaluating the potential effects of cumulative anticholinergic exposure. Several scales exist for quantifying anticholinergic exposure cross-sectionally; [4, 9-17] however, only two published measures [developed by Gray et al. (cumulative dose) and Campbell et al. (average daily dose)] allow for the extrapolation of anticholinergic burden scale scores over time [5, 6]. The applicability of anticholinergic scales and measures for use in the United States (US) observational studies was recently reviewed by Lozano-Ortega et al. [18] That review concluded that both Gray's cumulative dose measure, which considers patient-specific dosing [5], and Campbell's average daily dose measure [6], which considers anticholinergic potency, could be implemented in administrative claims data. However, as both anticholinergic dose and theoretical potency have individually been identified as contributors to anticholinergic burden, a measure that considers both could potentially capture the impact of the interaction between patient-specific dosing and presumed anticholinergic activity. To try to fill this gap, the Cumulative Anticholinergic Burden (CAB) measure was developed, which considers both dosing intensity and anticholinergic potency [based upon the Anticholinergic Cognitive Burden (ACB) scale] in its calculation [19]. Such a measure may provide a more robust 
method to capture cumulative anticholinergic exposure. However, the $\mathrm{CAB}$ measure has not yet been validated through its application in administrative data or through its comparison with existing measures.

To expand upon the recent review of anticholinergic burden scales and measures [18], the properties of the $\mathrm{CAB}$ measure were compared in this study against those of existing measures of anticholinergic exposure; the compatibility of all three measures for use in observational studies based on administrative claims data was also assessed.

\section{METHODS}

Descriptive characteristics of the $\mathrm{CAB}$ measure, steps involved in its implementation, and the measure output were evaluated against the same parameters for existing measures of cumulative anticholinergic exposure to determine their suitability for application in administrative claims analyses. Data from a large US health dataset were used in the evaluation.

\section{Descriptive Comparison of the Measures}

The following details of each measure have been summarized: data requirements for implementation; whether it considers anticholinergic cumulative exposure and potency as well as dose; the disease context for which the measure was developed; whether its development was based on a specific anticholinergic scale; its flexibility for use with all anticholinergic scales; its mathematical properties (e.g., average vs. aggregated score; score boundaries); the definition of exposure period; and considerations for the categorization of the resulting scores (Table 1). Other potential measures were also considered initially, including the Drug Burden Index with a modification to extrapolate anticholinergic burden longitudinally $[20,21]$. However, it was not included here as it does not consider anticholinergic potency and would therefore likely have similar limitations as those of the cumulative dose measure [17]. Additional details on the characteristics of anticholinergic measures assessed can be found in this published review [18].

\section{Quantitative Evaluation of the Measures}

The three measures were applied in a claims database to determine their suitability for use in retrospective studies relying on administrative data, and to evaluate correlations between the measures.

\section{Data Source}

Data from the US-based Truven MarketScan databases from 2012 to 2015 were used. These databases contain nationally representative healthcare data on patients insured commercially, or with employer-sponsored supplemental Medicare coverage. Data include demographics, diagnoses, records of outpatient and inpatient medical services, and pharmacy claims for over 84 million people linked at the individual level.

\section{Cohort Identification}

A $2.5 \%$ random sample was selected from individuals in the Truven MarketScan dataset aged $\geq 65$ years between January 1, 2012 and December 31, 2014. The sample was computerselected using a random number generator where all individuals aged $\geq 65$ years had an equal likelihood of being selected. Cohort members were enrolled on the first visit during the identification period at which an individual was $\geq 65$ years old (index date). A minimum of 12 months of pharmaceutical prescription data were required after enrolment to ensure that anticholinergic exposure could be estimated consistently across all cohort members.

\section{Scale Selection}

Although several anticholinergic scales with a hierarchical anticholinergic weighting system exist, the ACB scale was selected for the implementation of the three evaluated measures as it is a validated scale with a wide coverage of medications with anticholinergic effects and 
Table 1 Features of anticholinergic burden measures

\begin{tabular}{llll}
\hline Feature & Average daily score [6] Cumulative dose [5] & Cumulative anticholinergic \\
burden
\end{tabular}

Data requirements for implementation in administrative database studies

\begin{tabular}{|c|c|c|c|}
\hline Medication name & Yes & Yes & Yes \\
\hline Medication dose & No & Yes & Yes \\
\hline Days supplied & No & Yes & Yes \\
\hline $\begin{array}{l}\text { Minimum-effective } \\
\text { dose }\end{array}$ & No & Yes $[29]^{a}$ & No \\
\hline $\begin{array}{l}\text { Daily dose of } \\
\text { dispensed } \\
\text { medications }\end{array}$ & No & No & $\mathrm{Yes}^{\mathrm{a}}$ \\
\hline $\begin{array}{l}\text { Developed within the } \\
\text { context of a specific } \\
\text { disease/condition? }\end{array}$ & No & No & No \\
\hline $\begin{array}{l}\text { Built from a specific } \\
\text { anticholinergic } \\
\text { burden scale? }\end{array}$ & $\begin{array}{l}\text { Yes, ACB scale but can } \\
\text { accommodate any scale }\end{array}$ & No & $\begin{array}{l}\text { Yes, ACB scale but can } \\
\text { accommodate any scale }\end{array}$ \\
\hline $\begin{array}{l}\text { Can any scale be } \\
\text { considered for this } \\
\text { measure? }\end{array}$ & Yes & $\mathrm{Yes}^{\mathrm{b}}$ & Yes \\
\hline $\begin{array}{l}\text { Does it consider } \\
\text { duration of } \\
\text { exposure? }\end{array}$ & Yes & $\mathrm{Yes}^{\mathrm{c}}$ & Yes \\
\hline $\begin{array}{l}\text { Does it consider } \\
\text { cumulative } \\
\text { exposure? }\end{array}$ & Yes & Yes & Yes \\
\hline $\begin{array}{l}\text { Does the calculation } \\
\text { consider dose? }\end{array}$ & No & Yes & Yes \\
\hline $\begin{array}{l}\text { Does it consider } \\
\text { residual } \\
\text { anticholinergic } \\
\text { effect? }\end{array}$ & No & No & No \\
\hline $\begin{array}{l}\text { What does the } \\
\text { measure estimate }\end{array}$ & $\begin{array}{l}\text { Average daily anticholinergic } \\
\text { exposure }\end{array}$ & $\begin{array}{l}\text { Cumulative total standardized } \\
\text { daily dose }\end{array}$ & $\begin{array}{l}\text { Cumulative anticholinergic } \\
\text { exposure }\end{array}$ \\
\hline Score boundaries & $\begin{array}{l}\text { Lower bound: 0, upper bound: } \\
\text { depends on the scale } \\
\text { considered (theoretical upper } \\
\text { bound) }\end{array}$ & $\begin{array}{l}\text { Lower bound: 0, upper bound: } \\
\text { infinity (theoretical upper } \\
\text { bound) }\end{array}$ & $\begin{array}{l}\text { Lower bound: } 0 \text {, upper } \\
\text { bound: infinity (theoretical } \\
\text { upper bound) }\end{array}$ \\
\hline
\end{tabular}


Table 1 continued

\begin{tabular}{|c|c|c|c|}
\hline Feature & Average daily score [6] & Cumulative dose [5] & $\begin{array}{l}\text { Cumulative anticholinergic } \\
\text { burden }\end{array}$ \\
\hline $\begin{array}{l}\text { Suggested score } \\
\text { categories }\end{array}$ & $\begin{array}{l}0: 0-0.49 ; 1: 0.50-1.49 ; 2: \\
1.50-2.49 ; \text { etc }\end{array}$ & $\begin{array}{l}\text { No use; } 1-7 ; 7-17 ; 17-34 \\
\quad \geq 34\end{array}$ & Study-specific \\
\hline $\begin{array}{l}\text { Method for } \\
\text { determining score } \\
\text { categories }\end{array}$ & Arbitrary & $\begin{array}{l}\text { Based on clinical interpretability } \\
\text { and the observed exposure } \\
\text { distribution within the study } \\
\text { sample }\end{array}$ & $\begin{array}{l}\text { May be informed by } \\
\text { assessment of the } \\
\text { distribution of the } \\
\text { empirically observed } \\
\text { outcomes }\end{array}$ \\
\hline $\begin{array}{l}\text { Score depends on } \\
\text { length of study } \\
\text { period? }\end{array}$ & No & Yes & Yes \\
\hline \multicolumn{4}{|c|}{$\begin{array}{l}A C B \text { anticholinergic cognitive burden } \\
\text { a Dose may need to be informed by other sources } \\
\text { b The cumulative dose measure is not dependent on scale scores, but different scales can be considered for determining the } \\
\text { medications that will be included in the estimation of the score. The authors have focused on high-potency anticholinergics } \\
\text { only }\end{array}$} \\
\hline
\end{tabular}

the inclusion of numerous high-potency medications (see Online Resource Figure 2) [22]. Although the ACB scale has been used in other jurisdictions [23-25], as it was developed in the US it was expected to have better coverage of medications included within this dataset than those developed outside the US [18].

\section{Data Evaluation for Measure Implementation}

A descriptive evaluation of the data and steps required for implementation of the three measures was conducted. Each measure was evaluated based on the extent of data cleaning and merging required, the ease of extraction and the amount of matching of medication information with the US Food and Drug Administration's National Drug Codes (NDC).

Various degrees of data cleaning were required to implement each measure, and to merge medication names, routes of administration, tablet strength and unit of the active ingredient. Medication characteristics missing from the dataset were extracted from the NDC codes available in MarketScan [26].

\section{Measurement of Cumulative Anticholinergic Exposure}

Cumulative anticholinergic exposure was calculated for a 1-year period per cohort member, according to the average daily dose, cumulative dose and $\mathrm{CAB}$ measures. The 1-year exposure period was selected to align with exposure periods in previous studies $[6,15]$. Example calculations are presented in Online Resource Fig. 1.

\section{Average Daily Dose Measure}

The average daily dose measure [6] is calculated by summing the total anticholinergic potency (according to the ACB scale) of all anticholinergics prescribed over the period considered by the ACB scales and dividing the resulting value by the number of days in the period, as follows: 


$$
\begin{aligned}
& \text { Mean total ACB score } \\
& =\frac{\sum(\text { Drug A \# days supplied } \times \text { ACB score })+(\text { Drug B \# days supplied } \times \text { ACB score })+(\text { Drug X ... })}{\# \text { days in the exposure period }} .
\end{aligned}
$$

\section{Cumulative Dose Measure}

To calculate scores based on the cumulative dose measure [5], medication doses are first standardized and then summed to derive an estimate of cumulative exposure, described as the cumulative total standardized daily dose (TSDD) [27, 28]. Steps to calculate TSDD are: (1) calculate total medication dose for each prescription dispensation of a medication considered by an anticholinergic scale like the ACB scale, by multiplying the tablet strength by the number of tablets dispensed; (2) for each prescription dispensation, calculate the standardized daily dose (SDD) by dividing the estimated total medication dose by the minimum-effective dose per day (MED) recommended for use in older adults as per Semla et al.; [29] and (3) for each participant, sum the SDD for all anticholinergic pharmacy dispensations during the exposure period to generate a TSDD. The resulting TSDD is then categorized into "no use" (score of 0 ); 1-90; 91-365; 366-1095; or greater than 1095, with cut points based on clinical interpretability and the observed exposure distribution.

\section{Cumulative Anticholinergic Burden Measure}

The CAB measure was calculated using a novel method based on Gray et al.'s cumulative dose measure, but with the inclusion of medication dosing [5]. Cumulative exposure was thus calculated taking into account both drug-specific properties (i.e., anticholinergic activity) and patient-specific dosing. The World Health Organization (WHO) defined daily dose (DDD), the average daily maintenance dose for a medication's main indication in adults, was used to standardize dosing across different medications, and the drug-specific ACB score provided strength of anticholinergic activity [30]. Steps to estimate cumulative exposure were: (1) determine the DDD [30, 31] of each medication considered by the ACB scale; (2) calculate the standardized daily dose (SDD) for each anticholinergic dispensing according to the following equation:

$$
\mathrm{SDD}=\frac{\text { Number of Daily Units } \times \text { Unit Dose }}{\text { DDD }} .
$$

(3) multiply the SDD by the medication's ACB scale score to yield a drug- and patientspecific measure of standardized daily anticholinergic exposure (SDACE); (4) sum the drug-specific SDACE for all anticholinergic medications for individuals treated with multiple anticholinergic medications on a given day to give a summed standardized daily anticholinergic exposure (SumSDACE); and (5) calculate cumulative exposure by summing SumSDACE for all days during the exposure period. As DDDs are often unavailable in administrative databases, they were extracted from the WHO Collaborating Centre for Drug Statistics Methodology website [32]. An outline of the steps involved in calculating the $\mathrm{CAB}$ are provided in Online Resource Figure 3.

\section{Statistical Analysis}

Demographic characteristics of the cohort, overall and according to anticholinergic exposure level, were summarized using means and standard deviations (SD) for continuous variables and counts and percentages for categorical variables.

A data-cleaning algorithm was applied to handle clinically implausible values, based on assumptions regarding the most likely data errors responsible, and values adjusted accordingly. Briefly, SDDs above 10 were considered highly unlikely and the following adjustments were made: SDDs $\geq 10$ and $<100$ were divided 
by 10 , SDDs $\geq 100$ and $<1000$ were divided by 100 , and SDDs $\geq 1000$ and $<10,000$ were divided by 1000 , and so forth.

Measure scores were estimated among those with anticholinergic exposure only. Variability in overall scores for each measure of cumulative anticholinergic exposure was assessed by means (SD) and medians [interquartile range (IQR)]. Note that the absolute values of scores are not directly comparable across measures due to inherent differences in calculation methods, and each measure maps to a different range of values. Spearman's correlation coefficients were calculated to assess inter-measure correlations of estimated scores.

This article does not contain any new studies with human or animal subjects performed by any of the authors, and, as such, informed consent of individuals was not required. The dataset came from the US-based Truven MarketScan databases from 2012 to 2015.

\section{RESULTS}

\section{Descriptive Comparison of the Measures}

In the descriptive comparison of the $\mathrm{CAB}$ measure against the other two measures (Table 1), all were considered suitable for implementation in observational studies using claims data. Based on the data requirements, all measures consider medication name, and both the cumulative dose and $\mathrm{CAB}$ consider dose and days supplied. The $\mathrm{CAB}$ does not incorporate the minimum-effective dose, but it does incorporate the daily dose of dispensed medications, which neither the average daily dose nor cumulative dose measures do. Based on these characteristics, the data requirements for each measure can be satisfied by administrative datasets containing outpatient prescription dispensing information. In the more general comparison of characteristics, none of the measures were developed within the context of a specific disease or condition, nor do any of them consider residual anticholinergic effect. While each of the three measures can accommodate any anticholinergic burden scale, as the cumulative dose measure does not consider potency, it is limited to anticholinergic exposure of medications considered by the selected scale; the other two measures can be adapted to consider anticholinergic medications additional to the included scale. This ability to accommodate any scale is important, as researchers may choose scales more suitable to their research objectives.

\section{Quantitative Evaluation of the Measures}

The mean (SD) age of the overall cohort $(n=99,742)$ was 73.1 (7.6) years. Over $60 \%$ of the cohort was between 65 and 75 years of age, and almost 55\% were women. The cohort was primarily composed of individuals residing in southern states $(31.6 \%)$, while the northeast and north central were comparably represented (22.8\% and $25.4 \%$, respectively). Additional demographic characteristics of the cohort are summarized in Table 2.

Of the 99,742 members in the cohort, $56.1 \%$ were prescribed one or more anticholinergics during the 1-year period after their index date (Table 2). The mean (SD) age was slightly higher among those treated with anticholinergics [73.8 (7.8) years] compared to those without anticholinergic exposure [72.2 (7.3) years], as was the percentage of females $(57.7 \%$ among those treated with anticholinergics, vs. $51.4 \%$ among those without anticholinergic exposure). Both groups were similar in their geographic distribution.

\section{Data Evaluation for Measure Implementation}

To derive anticholinergic exposure using the average daily dose measure, medications within the ACB scale were matched to NDCs in the MarketScan data. Most data fields required for estimating average daily dose are available in MarketScan, and only moderate data cleaning was required. As NDC codes are reported in MarketScan, medication names could easily be extracted.

As the cumulative dose measure incorporates additional medication characteristics, including dose, tablet strength and MED information, more data cleaning and merging was required 
Table 2 Baseline characteristics of cohort

\begin{tabular}{|c|c|c|c|c|c|c|}
\hline & \multirow{2}{*}{$\begin{array}{l}\text { General population } \\
n=99,742\end{array}$} & \multicolumn{5}{|c|}{ By anticholinergic exposure } \\
\hline & & \multicolumn{3}{|c|}{$\begin{array}{l}\text { Treated with anticholinergics } \\
n=55,969\end{array}$} & \multicolumn{2}{|c|}{$\begin{array}{l}\text { No anticholinergic exposure } \\
n=43,773\end{array}$} \\
\hline \multicolumn{7}{|l|}{ Age (years) } \\
\hline Mean (SD) & $73.1(7.6)$ & \multicolumn{2}{|c|}{$73.8(7.8)$} & \multicolumn{2}{|r|}{$72.2(7.3)$} & \\
\hline \multirow[t]{2}{*}{ Median $[\mathrm{IQR}]$} & $71[66,78]$ & \multicolumn{2}{|c|}{$72[67,79]$} & \multicolumn{2}{|r|}{$70[66,77]$} & \\
\hline & $n$ & $\%$ & $n$ & $\%$ & $n$ & $\%$ \\
\hline \multicolumn{7}{|c|}{ Age categories (years) } \\
\hline $65<70$ & 42,828 & 42.9 & 21,710 & 38.8 & 21,118 & 48.2 \\
\hline $70<75$ & 20,055 & 20.1 & 11,246 & 20.1 & 8809 & 20.1 \\
\hline $75<80$ & 15,308 & 15.3 & 9290 & 16.6 & 6018 & 13.7 \\
\hline $80<85$ & 11,543 & 11.6 & 7228 & 12.9 & 4315 & 9.9 \\
\hline$\geq 85$ & 10,008 & 10.0 & 6495 & 11.6 & 3513 & 8.0 \\
\hline \multicolumn{7}{|l|}{ Sex } \\
\hline Female & 54,806 & 54.9 & 32,313 & 57.7 & 22,493 & 51.4 \\
\hline Male & 44,936 & 45.1 & 23,656 & 42.3 & 21,280 & 48.6 \\
\hline \multicolumn{7}{|l|}{ Region } \\
\hline Northeast & 22,774 & 22.8 & 12,692 & 22.7 & 10,082 & 23.0 \\
\hline North central & 25,378 & 25.4 & 14,353 & 25.6 & 11,025 & 25.2 \\
\hline South & 31,478 & 31.6 & 18,622 & 33.3 & 12,856 & 29.4 \\
\hline West & 17,946 & 18.0 & 9101 & 16.3 & 8845 & 20.2 \\
\hline Unknown & 804 & 0.8 & 399 & 0.7 & 405 & 0.9 \\
\hline Multiple regions & 1362 & 1.4 & 802 & 1.4 & 560 & 1.3 \\
\hline
\end{tabular}

$S D$ standard deviation, $I Q R$ interquartile range

than for the average daily dose measure. If the selected scale included medications with a MED specific to route of administration, routes in the administrative data may require recategorization to match those in MED definitions before merging in MED. For medication routes with an unavailable MED, DDD was used as a proxy; in the absence of both estimates, DDD was informed by expert opinion.

The CAB measure relies on DDD; as DDD is route-specific, routes in the administrative data may require recategorization to match those in DDD definitions before merging in DDD. Like the cumulative dose measure, the $\mathrm{CAB}$ measure considers quantity in its calculations; this information is likely to be available in administrative datasets but may require some cleaning of negative and unreasonably large values.

Note that data cleaning and merging steps are database-specific, depending on the level and quality of the prescription data of the database being accessed. The steps indicated here were influenced by data availability and the quality of the MarketScan dispensation information. 


\section{Cumulative Anticholinergic Exposure Scores and Correlations}

Median (IQR) scores among those treated with anticholinergics $(n=55,969)$ during the year of follow-up were $0.9(0.3-1.5)$ for average daily dose, 16.9 (7.3-33.9) for the cumulative dose, and 203 (68-500) for the $\mathrm{CAB}$ measure (Table 3). Cumulative exposure data were nonnormally distributed across all three measures (Fig. 1).

The average daily dose, cumulative dose, and $\mathrm{CAB}$ scores were all highly correlated; from $r^{2}=0.74$ for the correlation of the cumulative dose and $\mathrm{CAB}$ measures, to $r^{2}=0.83$ for the correlation of average daily dose and $\mathrm{CAB}$ measures (Fig. 1).

\section{DISCUSSION}

Measures of cumulative anticholinergic exposure assess the overall anticholinergic burden experienced by individuals over time by extrapolating scores on anticholinergic burden scales longitudinally. With a growing interest in measuring the impact of cumulative anticholinergic exposure, an understanding of which measures are well suited for application to administrative claims data is of value for researchers designing studies of associated health outcomes. In this study, a new measure of cumulative anticholinergic exposure, the
$\mathrm{CAB}$, was introduced and compared in administrative data alongside two published measures $[5,6]$.

The three measures considered here were deemed well suited for their application in observational studies relying on administrative health data. Inter-measure score correlations were high across all pairs of measures $\left(r^{2}=0.74-0.83\right)$, suggesting a similar likelihood of capturing true associations between cumulative anticholinergic exposure and clinical outcomes of interest.

The CAB measure offers an advantage in that it is a summative measure that considers both dose and anticholinergic potency of medications over time. This is important as high-dose as well as high-potency anticholinergics are associated with increased risk of cognitive impairment in older adults. However, it is plausible that the $\mathrm{CAB}$ may offer no additional benefit in quantifying the associations between cumulative burden and clinical outcomes. To allow for a better understanding of the clinical impact of cumulative anticholinergic exposure across different patient populations, future research should focus on: (1) the consistent application of a measure that would allow easier comparison of results from different studies in this area and help researchers understand the relative effects of exposure in different populations and in examining different outcomes; (2) defining thresholds of exposure above which action should be taken in routine clinical

Table 3 One-year ${ }^{\mathrm{a}}$ cumulative anticholinergic exposure scores based on the ACB scale

\begin{tabular}{|c|c|c|c|c|}
\hline \multirow[t]{2}{*}{ Measure } & \multicolumn{2}{|c|}{ All cohort members $(n=99,742)$} & \multicolumn{2}{|c|}{$\begin{array}{l}\text { Cohort members with } \\
\text { anticholinergic dispensations } \\
(n=55,969)\end{array}$} \\
\hline & $\overline{\text { Median (IQR) }}$ & Range & Median (IQR) & Range \\
\hline $\begin{array}{l}\text { Average daily dose (including days with no } \\
\text { anticholinergics) }\end{array}$ & $0.1(0.0,0.9)$ & $0.0,16.1$ & $0.9(0.3,1.5)$ & $0.0,16.1$ \\
\hline Cumulative dose & $2.9(0.0,19.7)$ & $0.0,390.3$ & $16.9(7.3,33.9)$ & $0.1,390.3$ \\
\hline Cumulative Anticholinergic Burden & $24(0,240)$ & $0,11,609$ & $203(68,500)$ & $0,11,609$ \\
\hline
\end{tabular}

$I Q R$ interquartile range

a The one-year exposure period was arbitrary; the appropriate exposure period may be disease- and outcome-specific, so appropriate consideration should be given on a case-by-case basis 


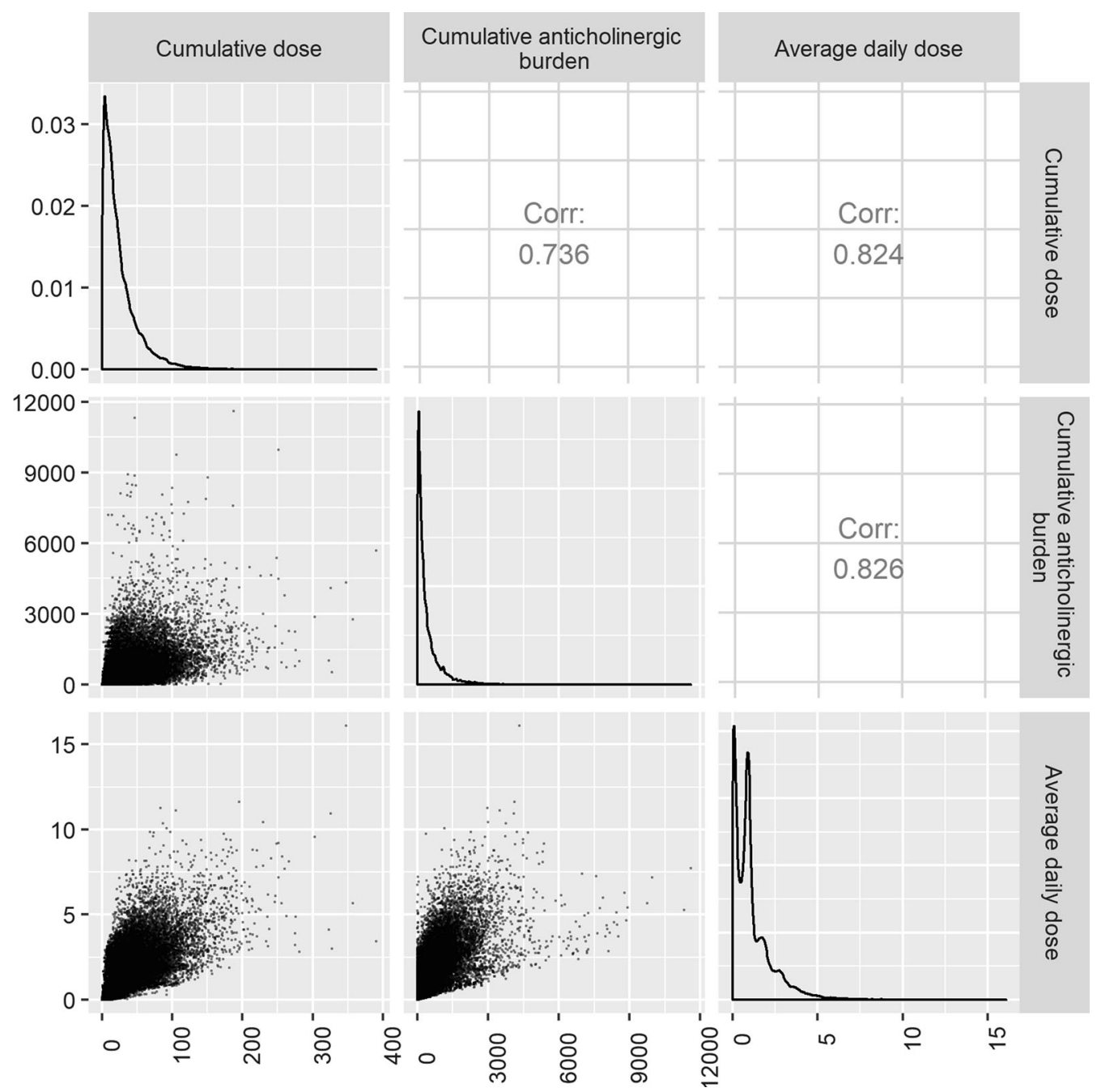

Fig. 1 Spearman's correlations of anticholinergic burden measures estimated over a one-year exposure period. Measures estimated in the context of the ACB scale.

practice; (3) applying the $\mathrm{CAB}$ measure alongside one or more other measures to compare their abilities to predict clinical outcomes; and (4) the evaluation of whether reducing anticholinergic burden, either through dose reduction, restricted duration, or both, translates to clinical improvement in prospective trials. Another potential next step would be the development of a model that varies the specific anticholinergics considered in the cumulative burden calculation to examine whether a total scale score versus subsets of anticholinergics (e.g., only high-potency anticholinergics) works better for predicting key outcomes.
The diagonal presents density plots of the estimated scores while the lower section of the figure presents scatter plots of the corresponding measures

A strength of this study is the estimation of anticholinergic burden in a general population sample, these data can therefore provide benchmarks for plausible ranges of each measure for comparison with the results of future studies. In this study, all medications considered by the ACB scale were included in the calculation of the scores, rather than only the strong anticholinergics, as was done by Gray et al.[5]. However, the impact of multiple mild anticholinergics taken simultaneously has not been well established and may be outcomespecific. Future studies should consider a comprehensive inclusion of medications for testing 
the hypothesis that $\mathrm{CAB}$ from all medications (including those categorized as mild anticholinergics) may contribute to adverse outcomes through an anticholinergic pathway.

An important limitation of these analyses relates to how anticholinergic medications are used in real-world settings. Anticholinergics are a heterogeneous class of medications, with significant variability in patterns of use related to individual patient characteristics, disease attributes or symptom severity. For example, antihistamines may be used intermittently for control of itching or allergic symptoms, whereas antidepressants are intended for daily use. The measures to calculate anticholinergic exposure described in this study are based on an assumption that exposure is distributed evenly across a defined timeframe; however, this pragmatic approach may not reflect the dynamic nature of clinical care. A further limitation of using claims data to assess anticholinergic exposure is the inability to assess medication adherence, as available data report medication dispensations rather than use. If necessary, adherence may be estimated using standard measures focusing on the frequency and timing of prescription refills. Finally, careful considerations must be made in the selection of the most appropriate anticholinergic scale, with respect to which medications are available as well as the variability of over-thecounter medications in different countries. As such, the recommendations presented here are limited to observational studies relying on administrative claims data in the US. A further consideration with respect to scale selection is that many scales are validated in an older population, and thus the population to which each scale is applied should be examined. In the present study, as the ACB was validated among older adults, its use among adults aged $\geq 65$ years was warranted.

\section{CONCLUSION}

The CAB measure, which considers both anticholinergic dose and potency, is a viable tool for measuring cumulative anticholinergic exposure in future observational studies relying on US administrative claims data. Future research is needed to compare the predictive ability of the $\mathrm{CAB}$ against that of other available metrics across relevant clinical outcomes associated with high anticholinergic burden.

\section{ACKNOWLEDGEMENTS}

Funding. The study was initiated and funded by Astellas Pharma Global Development, Inc. Astellas Pharma Global Development Inc. also funded the journal's article processing charges and Open Access fee. All authors had full access to all of the data in this study and take complete responsibility for the integrity of the data and accuracy of the data analysis.

Authorship. All named authors meet the International Committee of Medical Journal Editors (ICMJE) criteria for authorship for this article, take responsibility for the integrity of the work as a whole, and have given their approval for this version to be published.

Medical Writing and/or Editorial Assistance. Editorial support for this manuscript was provided by Kath Quayle and Meagan Harwood. Kath Quayle provided consultation services to, and Meagan Harwood is an employee of, Broadstreet HEOR which received payment from Astellas in the conduct of this study.

Disclosures. Shelagh M Szabo is an employee of Broadstreet HEOR, which received payment from Astellas to conduct the study. Greta Lozano-Ortega is an employee of Broadstreet HEOR, which received payment from Astellas to conduct the study. Antoinette Cheung is an employee of Broadstreet HEOR, which received payment from Astellas to conduct the study. Basia Rogula is an employee of Broadstreet HEOR, which received payment from Astellas to conduct the study. Brandon Suehs is an employee of Comprehensive Health Insights, Inc., a subsidiary of Humana Inc., who has in the past received payment from Astellas for consultation in the conduct of research studies. Eleanor Caplan is an employee of 
Comprehensive Health Insights, Inc., a subsidiary of Humana Inc., who has in the past received payment from Astellas for consultation in the conduct of research studies. Adrian Wagg has received payment from Astellas for consultation in the conduct of this study as well as prior grants for research. Noll Campbell received payment from Astellas for consultation in the conduct of this study. Roger Dmochowski received payment from Astellas for consultation in the conduct of this study. Daniel $\mathrm{Ng}$ is an employee of Astellas Pharma Global Development Inc.

Compliance with Ethics Guidelines. This article does not contain any new studies with human or animal subjects performed by any of the authors, as such, informed consent of individuals was not required. The dataset came from the US-based Truven MarketScan databases from 2012-2015.

Data Availability. Access to anonymized individual participant level data will not be provided for this trial as it meets one or more of the exceptions described on www. clinicalstudydatarequest.com under "Sponsor Specific Details for Astellas".

Open Access. This article is distributed under the terms of the Creative Commons Attribution-NonCommercial 4.0 International License (http://creativecommons.org/licenses/ by-nc/4.0/), which permits any noncommercial use, distribution, and reproduction in any medium, provided you give appropriate credit to the original author(s) and the source, provide a link to the Creative Commons license, and indicate if changes were made.

\section{REFERENCES}

1. Bostock CV, Soiza RL, Mangoni AA. Associations between different measures of anticholinergic drug exposure and Barthel Index in older hospitalized patients. Ther Adv Drug Saf. 2013;4(6):235-45. https://doi.org/10.1177/2042098613500689.

2. Purves P, Augustine GJ, Fitzpatrick D, Katz LC, LaMantia A-S, McNamara JO et al. Neuroscience, 2nd edition. Sinauer, Sunderland. 2001. https:// www.ncbi.nlm.nih.gov/books/NBK10834/.

3. Fox C, Richardson K, Maidment ID, Savva GM, Matthews FE, Smithard D, et al. Anticholinergic medication use and cognitive impairment in the older population: the medical research council cognitive function and ageing study. J Am Geriatr Soc. $2011 ; 59(8): 1477-83$.

4. Boustani MC, Munger S, Maidment I, Fox C. Impact of anticholinergics on the aging brain: a review and practical application. Aging Health. 2008;4(3):311-20.

5. Gray SL, Anderson ML, Dublin S, et al. Cumulative use of strong anticholinergics and incident dementia: a prospective cohort study. JAMA Intern Med. 2015;175(3):401-7. https://doi.org/10.1001/ jamainternmed.2014.7663.

6. Campbell NL, Perkins AJ, Bradt P, Perk S, Wielage RC, Boustani MA, et al. Association of anticholinergic burden with cognitive impairment and health care utilization among a diverse ambulatory older adult population. Pharmacotherapy. 2016;36(11):1123-31. https://doi.org/10.1002/ phar. 1843 .

7. Richardson K, Fox C, Maidment I, Steel N, Loke YK, Arthur A, et al. Anticholinergic drugs and risk of dementia: case-control study. BMJ. 2018;361:k1315. https://doi.org/10.1136/bmj. k1315.

8. Szabo SM, Gooch K, Schermer C, Walker D, LozanoOrtega G, Rogula B, Deighton A, Vonesh E, Campbell N. Association between cumulative anticholinergic burden and falls and fractures in patients with overactive bladder: US-based retrospective cohort study. BMJ Open. 2019. https://doi. org/10.1136/bmjopen-2018-026391.

9. Ehrt U, Broich K, Larsen JP, Ballard C, Aarsland D. Use of drugs with anticholinergic effect and impact on cognition in Parkinson's disease: a cohort study. J Neurol Neurosurg Psychiatry. 2010;81(2):160-5. https://doi.org/10.1136/jnnp.2009.186239.

10. Carnahan RM, Lund BC, Perry PJ, Pollock BG, Culp KR. The anticholinergic drug scale as a measure of drug-related anticholinergic burden: associations with serum anticholinergic activity. J Clin Pharmacol. 2006;46(12):1481-6. https://doi.org/10. $1177 / 0091270006292126$.

11. Sittironnarit G, Ames D, Bush AI, Faux N, Flicker L, Foster J, et al. Effects of anticholinergic drugs on cognitive function in older Australians: results from the AIBL study. Dement Geriatr Cogn Disord. 2011;31(3):173-8. https://doi.org/10.1159/ 000325171. 
12. Rudolph JL, Salow MJ, Angelini MC, McGlinchey RE. The anticholinergic risk scale and anticholinergic adverse effects in older persons. Arch Intern Med. 2008;168(5):508-13. https://doi.org/10.1001/ archinternmed.2007.106.

13. Ancelin ML, Artero S, Portet F, Dupuy AM, Touchon J, Ritchie K. Non-degenerative mild cognitive impairment in elderly people and use of anticholinergic drugs: longitudinal cohort study. BMJ. 2006;332(7539):455-9. https://doi.org/10.1136/ bmj.38740.439664.DE.

14. Naples JG, Marcum ZA, Perera S, Gray SL, Newman $\mathrm{AB}$, Simonsick EM, et al. Concordance between anticholinergic burden scales. J Am Geriatr Soc. 2015;63(10):2120-4.

15. Han L, Agostini JV, Allore HG. Cumulative anticholinergic exposure is associated with poor memory and executive function in older men. J Am Geriatr Soc. 2008;56(12):2203-10. https://doi.org/ 10.1111/j.1532-5415.2008.02009.x.

16. Aizenberg D, Sigler M, Weizman A, Barak Y. Anticholinergic burden and the risk of falls among elderly psychiatric inpatients: a 4-year case-control study. Int Psychogeriatr. 2002;14(3):307-10.

17. Hilmer SN, Mager DE, Simonsick EM, et al. A drug burden index to define the functional burden of medications in older people. Arch Intern Med. 2007;167(8):781-7. https://doi.org/10.1001/ archinte.167.8.781.

18. Lozano-Ortega G, Johnston K, Cheung A, Wagg A, Campbell N, Dmochowski R, et al. Review of published anticholinergic scales and measures and assessment of their applicability in retrospective database analysis. Arch Gerontol Geriatr. 2019. https://doi.org/10.1016/j.archger.2019.05.010.

19. Lozano-Ortega G, Ng D, Johnston K, Cheung A, Guttschow A, Gooch K, et al. Assessment of anticholinergic burden scales and measures for estimating anticholinergic exposure in retrospective US database analyses. Value Health. 2018;21(S1):S211.

20. Wilson NM, Hilmer SN, March LM, Cameron ID, Lord SR, Seibel MJ, et al. Associations between drug burden index and physical function in older people in residential aged care facilities. Age Ageing. 2010;39(4):503-7. https://doi.org/10.1093/ageing/ afq053.

21. Hilmer SN, Mager DE, Simonsick EM, Ling SM, Windham BG, Harris TB, et al. Drug burden index score and functional decline in older people. Am J Med. 2009;122(12):1142. https://doi.org/10.1016/j. amjmed.2009.02.021.
22. Duran CE, Azermai M, Vander Stichele RH. Systematic review of anticholinergic risk scales in older adults. Eur J Clin Pharmacol. 2013;69(7):1485-96. https://doi.org/10.1007/s00228-013-1499-3.

23. Pfistermeister B, Tumena T, Gassmann KG, Maas R, Fromm MF. Anticholinergic burden and cognitive function in a large German cohort of hospitalized geriatric patients. PLoS ONE. 2017;12(2):e0171353. https://doi.org/10.1371/journal.pone.0171353.

24. O'Dwyer M, Maidment ID, Bennett K, Peklar J, Mulryan N, McCallion P, et al. Association of anticholinergic burden with adverse effects in older people with intellectual disabilities: an observational cross-sectional study. $\mathrm{Br} \mathrm{J}$ Psychiatry. 2016;209(6):504-10. https://doi.org/10.1192/bjp. bp.115.173971.

25. Cross AJ, George J, Woodward MC, Ames D, Brodaty $\mathrm{H}$, Wolfe $\mathrm{R}$, et al. Potentially Inappropriate Medication, Anticholinergic Burden, and Mortality in People Attending Memory Clinics. J Alzheimers Dis. 2017;60(2):349-58. https://doi.org/10.3233/ JAD-170265.

26. U.S. Food and Drug Administration. NDC Database File. In: U.S. Food and Drug Administration, editor. 2017. https://www.fda.gov/drugs/drugapprovalsand-databases/national-drug-code-directory.

27. Gray SL, LaCroix AZ, Blough D, Wagner EH, Koepsell TD, Buchner D. Is the use of benzodiazepines associated with incident disability? J Am Geriatr Soc. 2002;50(6):1012-8.

28. Hanlon JT, Boudreau RM, Roumani YF, Newman $\mathrm{AB}$, Ruby CM, Wright RM, et al. Number and dosage of central nervous system medications on recurrent falls in community elders: the Health, Aging and Body Composition study. J Gerontol A. 2009;64(4):492-8. https://doi.org/10.1093/gerona/ $\operatorname{gln} 043$.

29. Semla TP, Beizer JL, Higbee MD. Geriatric dosage handbook. 15th ed. Hudson: Lexicomp; 2010.

30. WHO Collaborating Centre for Drug Statistics Methodology. ATC/DDD Index. 2017. http://www. whocc.no/atc_ddd_index/.

31. WHO Collaborating Centre for Drug Statistics Methodology. Definition and general considerations. https://www.whocc.no/ddd/definition_and_ general_considera/.

32. WHO Collaborating Centre for Drug Statistics Methodology. 2017. https://www.whocc.no/. 